\title{
Analytical and Numerical Solution for H-type Darrieus Wind Turbine Performance at the Tip Speed Ratio of Below One
}

\author{
Pedram Ghiasia ${ }^{a}$ Gholamhassan Najafi*a*, Barat Ghobadiana ${ }^{\text {a }}$, Ali Jafari ${ }^{b}$ \\ a Department of Biosystems Engineering, Tarbiat Modares University, P.O. Box: 111-14115, Tehran, Iran. \\ ${ }^{b}$ Department of Agricultural Engineering, University of Tehran, P.O. Box: 6619-14155, Karaj, Iran.
}

\begin{abstract}
H-type Darrieus vertical axis wind turbines (VAWT) have omnidirectional movement capability and can get more power compared to other VAWTs at high tip speed ratios $(\lambda)$. However, its disadvantages are self-starting inability and low generated power at $\lambda$ less than 1 . The performance of H-type Darrieus wind turbine at $\lambda<1$ was studied using double multiple stream tube (DMST) model and two-dimensional computational fluid dynamic (CFD) simulation. In CFD simulation, the Unsteady Reynolds Averaged Navier-Stokes (URANS) equations were used and the turbulence model was solved with SST k- $\omega$ model. The performance of fifteen various wind turbines was determined at fourteen wind velocities by two solution methods. The effect of chord length, solidity, Reynolds number and Height to Diameter (H/D) ratio were investigated on generated torque, power and the time required to reach $\lambda=0.1$. Increasing in the moment of inertia due to the increasing in required time to reach $\lambda=0.1$. In the low TSRs, the wind turbines can generate higher torque and power in high Re numbers and solidities. The required time reduced by an increase in Re number and solidity. Finally, the best ratio of H/D of H-type Darrieus wind turbines was defined to improve the turbine performance.
\end{abstract}

Keywords: self-starting, DMST model, design parameters, wind energy, Vertical Axis Wind Turbine.

Article History: Received: 28 ${ }^{\text {th }}$ Sept 2020; Revised: $7^{\text {th }}$ Dec 2020; Accepted: 30 th Dec 2020; Available online: $2^{\text {nd }}$ January 2021

How to Cite This Article: Ghiasi, P., Najafi, G., Ghobadian, B., Jafari, A. (2021) Analytical and Numerical Solution for H-type Darrieus Wind Turbine Performance at the Tip Speed Ratio of Below One. Int. Journal of Renewable Energy Development, 10(2), 269-281 https://doi.org/10.14710/ijred.2021.33169

\section{Introduction}

Wind has become a fast-growing energy source due to its sustainability and eco-friendliness in comparison to other sources of energy such as fossil fuel (Wu, Bangga, \& Cao, 2019). The main obstacle in the sustainable development way are the fossil fuel and nuclear energy technologies that are accompanied by environmental degradation at local, regional, and global levels, which threatens human health now and in the future (Islam, Fartaj, \& Carriveau, 2011). Wind turbines are classified into two types: horizontal axis wind turbine (HAWT) and vertical axis wind turbine (VAWT) (Letcher, 2017). The HAWT type usually is used for large scale energy generation and the VAWT type can be implemented in small scales (Alam \& Golde, 2013). The VAWT can be divided into two types based on the power generation method; drag type and lift type (Sagharichi, Maghrebi, \& Arabgolarcheh, 2016). The Savonius wind turbine works with drag force and its blades tip speed is generally less than the wind velocity. In other words, $\lambda$ (tip speed ratio) value is less than one in this turbine (Abraham et al., 2012). The Darrieus wind turbine is classified as lift type because of the method wind force acts on the blades (Aslam Bhutta et al., 2012). Many researchers design a new VAWT to improve the performance or eliminate its deficiencies, such as low torque at low $\lambda$ and self-rotating problem (Kirke \& Paillard, 2017). High $\lambda$ is desirable because of higher power generation efficiency in this regime but to discover comprehensive information about the problem of the Darrieus wind turbine, we needed to investigate its performance at low $\lambda$.

Darrieus wind turbine designs were first patented in 1931 (Darrieus 1931). Many researchers studied the effects of design parameters on wind turbine performance (Delafin et al., 2016; Roy et al., 2017). Delafin et al., (2016) studied the effect of number of blades and solidity of VAWT on the power coefficient. Modifying the number of blades while keeping a constant solidity leads to very small changes in power curves. However, increased number of blades leads to lower Cp. Sun et al. (2020), reported that between 4 different moment of inertia of turbines, the highest moment coefficient corresponded to the Darrieus VAWT with the lowest moment of inertia. Hara, Hara, and Hayashi (2012) also concluded that with an increase in moment of inertia of the Darrieus wind turbine, the self-starting problem becomes more sever. Experiments in the wind tunnel showed that at high $\lambda$ of the rotor, the Darrieus wind turbine with low blade solidity could generate more power, but at lower $\lambda$, the high solidity wind turbine had greater $\mathrm{C}_{\mathrm{p}}$ (Roy et al.,

\footnotetext{
* Corresponding author: g.najafi@modares.ac.ir
} 
2017). The analytical study of straight-blade design of VAWT for asymmetric blade showed that the increment of Height/Diameter (H/D) of wind turbine increased the mass per height unit material, which in turn led to increased blade solidity and manufacturing costs (Islam et al., 2011). Several methods were defined to overcome the selfstarting problem of the Darrieus wind turbine; one was the use of camber airfoil. Beri and Yao (2011) showed that camber airfoils can improve self-starting of Darrieus wind turbine. Compared to asymmetric airfoils, the NACA2415 airfoil can reduce the time needed to reach $\lambda=1$. Another solution for improving the Darrieus wind turbine performance is pitch angle. The fixed pitch angle of $-2^{\circ}$ can increase the $\mathrm{Cp}$ by $6.6 \%$, compared to pitch angle of 0 degree (Rezaeiha, Kalkman, \& Blocken, 2017). Variable pitch angle is a better solution for Darrieus wind turbine to remove self-starting problem and improve performance. Moreover, the variable pitch angle can reach more angular velocity than fixed pitch angle (Kirke \& Paillard, 2017). Compared to the fixed pitch angle, the variable pitch angle can increase the $\mathrm{C}_{p}$ of Darrieus wind turbine (Abdalrahman, Melek, \& Lien, 2017; Oliveira, Carolina, \& Maia, 2017; Staelens, Saeed, \& Paraschivoiu, 2003). To overcome the self-starting problems of Darrieus wind turbines the blade with flap were investigated, results show that in the low TSR the blade with flap can improve the performance of the wind turbines (Liu et al., 2019).

One of the important keys in the using aerodynamic models to solve the VAWT performance problems is the angle of attack (AOA) calculation. The behavior of AOA of Darrieus wind turbines at $\lambda<1$ is different from that at $\lambda \geq 1$, yet the most available equations for calculating the $\mathrm{AOA}$ are developed for $\lambda \geq 1$. However, by modifying the previous equations of $\mathrm{AOA}$, the new equation is defined and used in double multiple stream tube (DMST) model at $\lambda<1$ to solve the Darrieus wind turbine performance equations. The effect of some design parameters, including blade solidity, height to diameters ratio (HDR) and chord length, on self-starting and performance of Darrieus wind turbine at $\lambda<1$ was studied. The computational fluid dynamic simulation was applied for every tests and the results were compared to those obtained from the analytical solution.

\section{Materials and Methods}

\subsection{The experiment scheme}

In this study, self-starting parameters and performance of fifteen different Darrieus wind turbines were investigated at $\lambda<1$. The self-starting parameter was the required time for reaching $\lambda=0.1$. This parameter was determined for five different VAWT types in various wind velocities. The wind velocity was in the range of $1-14 \mathrm{~m} \cdot \mathrm{s}^{-1}$ increasing in $1 \mathrm{~m} . \mathrm{s}^{-1}$ intervals. The fifteen types of Darrieus wind turbine had different moment of inertia, chord length and solidity. All of the wind turbines had three blades, $1.2 \mathrm{~m}^{2}$ rotor frontal area and NACA0020 airfoil type. Five types of the wind turbines with $16 \mathrm{~cm}$ chord length are shown in the Figure 1. Table 1 shows the Height to Diameter ratio (H/D), solidity, rotor frontal area, chord length, airfoil type and moment of inertia for fifteen different Darrieus wind turbines.

The rotation start depends on moment of inertia of rotor, friction of solid parts, generator and air resistance (rotation friction). Assuming that the rotation friction was constant with amount 1 for all wind turbines, the factors effective on the angular acceleration were torque and moment on inertia of the rotor. Based on the Newton's second law, the relationship between these parameters are as follow:

$$
I \ddot{\theta}+C \omega=T
$$

After calculating the generated torque, equations (2) and (3) were used for determination of the time needed to reach $\lambda=0.1$.

$$
\begin{aligned}
& \lambda_{0}=\frac{R \omega}{V_{\infty}} \\
& \ddot{\theta}=\frac{\omega}{t}
\end{aligned}
$$

Table 1

Specifications of H-type Darrieus wind turbines

\begin{tabular}{ccccccc}
\hline No & $\begin{array}{c}\text { Rotor } \\
\text { Solidity }\end{array}$ & $\begin{array}{c}\text { Height } \\
(\mathrm{m})\end{array}$ & $\begin{array}{c}\text { Diameter } \\
(\mathrm{m})\end{array}$ & H/D & $\begin{array}{c}\text { Chord Length } \\
(\mathrm{m})\end{array}$ & $\begin{array}{c}\text { Moment of Inertia } \\
\left(\mathrm{kg} . \mathrm{m}^{2}\right)\end{array}$ \\
\hline 1 & 0.3096 & 0.775 & 1.55 & 0.5 & 0.16 & 3.15 \\
2 & 0.4 & 1 & 1.2 & 0.83 & 0.16 & 2.01 \\
3 & 0.48 & 1.2 & 1 & 1.2 & 0.16 & 1.46 \\
4 & 0.5542 & 1.38 & 0.866 & 1.6 & 0.16 & 0.9 \\
5 & 0.6193 & 1.55 & 0.755 & 2 & 0.16 & 3.96 \\
6 & 0.3870 & 0.775 & 1.55 & 0.5 & 0.16 & 2.79 \\
7 & 0.5 & 1 & 1.2 & 0.83 & 0.2 & 1.59 \\
8 & 0.6 & 1.2 & 1 & 1.2 & 0.2 & 1.31 \\
9 & 0.6928 & 1.38 & 0.866 & 1.6 & 0.2 & 3.36 \\
10 & 0.7741 & 1.55 & 0.755 & 2 & 0.2 & 2.57 \\
11 & 0.4645 & 0.775 & 1.55 & 0.5 & 0.24 & 2.11 \\
12 & 0.6 & 1 & 1.2 & 0.83 & 0.24 & 1.76 \\
13 & 0.72 & 1.2 & 1 & 1.2 & 0.24 & \\
14 & 0.8314 & 1.38 & 0.866 & 1.6 & 0.24 & 0.24 \\
15 & 0.9290 & 1.55 & 0.755 & 2 & 0.24 \\
\hline
\end{tabular}




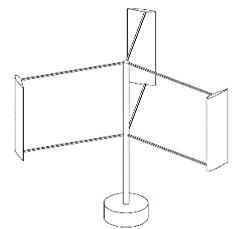

(A)

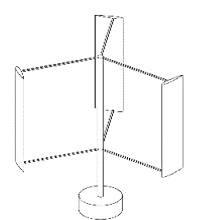

(B)

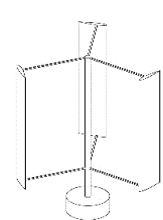

(C)

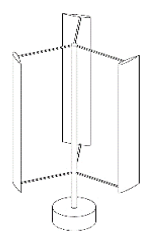

(D)

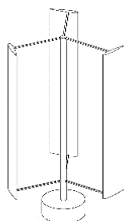

(E)

Fig. 1 Schematic of H-type Darrieus wind turbine in five H/D ratios

\subsection{Analytical model}

A DMST model, which was originally developed by (Paraschivoiu, 1988), was utilized in the present study for analysis. The model is a combination of the MST model and double actuator theory. Turbines were divided into two sections; upwind and downwind. The first step was to calculate the forces acting on the VAWT blades which required calculation of the value and direction of velocities. The velocities of upstream and downstream were different from the free velocity of wind (Figure 2). The $V_{e}$ is related to velocity region between up and down streams. The equations are as follow (Saber, Attia, \& El Gamal, 2015):

$$
\begin{aligned}
& V=u V_{\infty} \\
& V_{e}=(2 u-1) V_{\infty} \\
& V^{\prime}=u^{\prime}(2 u-1) V_{\infty}
\end{aligned}
$$

The local relative wind speed for the upstream section of rotor was determined by (Saeidi, Sedaghat, Alamdari, \& Alemrajabi, 2013):

$$
W=V_{\infty} \sqrt{\left(\lambda_{0}+u \sin (\theta)\right)^{2}+(u \cos (\theta))^{2}}
$$

Figure (3) shows the behavior of AOA at $\lambda$ less than 1 . At $\lambda<1$ and 135 to 225 degrees' azimuth angles, the wind acts as drag force on blades, so the angle of attack in this azimuth angle range must be greater than 90 degrees. Thus, equations (8) and (9) were used for calculating the AOA at $\lambda<1$.

$$
\begin{aligned}
& \alpha_{u}=\tan ^{-1}\left(\frac{u \cos (\theta)}{\lambda_{0}+u \sin (\theta)}\right) \\
& \alpha_{l}=\alpha_{u}+180\left(\left[\frac{\alpha_{u}}{\alpha_{u}+1}\right]-\left[\frac{\theta}{180}\right]^{*}\right)
\end{aligned}
$$

The calculation of the force on blades is needed to determine the induction factors which is derived from the blade element theory (Ahmadi-Baloutaki, 2016). The induction factors can be determined by combining the blade element theory and momentum theory for each stream tube at the rotor.

$$
\begin{aligned}
& u=\frac{\pi}{f_{u}+\pi} \\
& f_{u}=\frac{\sigma}{2 \pi} \int_{0}^{\pi} \quad\left(\frac{W}{V_{\infty}}\right)^{2}|\sec (\theta)| \\
& \left(C_{n} \cos (\theta)-C_{t} \sin (\theta)\right) d \theta
\end{aligned}
$$

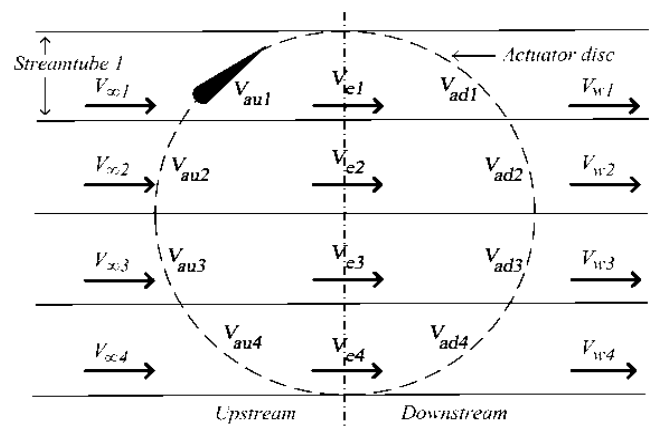

Fig. 2 Principle of multiple stream tube model with 4 stream tubes.

where the blade solidity is obtained as:

$$
\sigma=\frac{N c}{2 R}
$$

where $C_{n}$ and $C_{t}$ are the coefficients of normal and tangential components of the force, respectively. The $\mathrm{C}_{n}$ and $\mathrm{C}_{\mathrm{t}}$ which are calculated through equations (13) and (14), are functions of drag and lift coefficients and AOA of the blades:

$$
\begin{aligned}
& C_{n}=C_{L} \cos (\alpha)+C_{D} \sin (\alpha) \\
& C_{t}=C_{L} \sin (\alpha)-C_{D} \cos (\alpha)
\end{aligned}
$$

". the [] is the ceiling functions symbols.

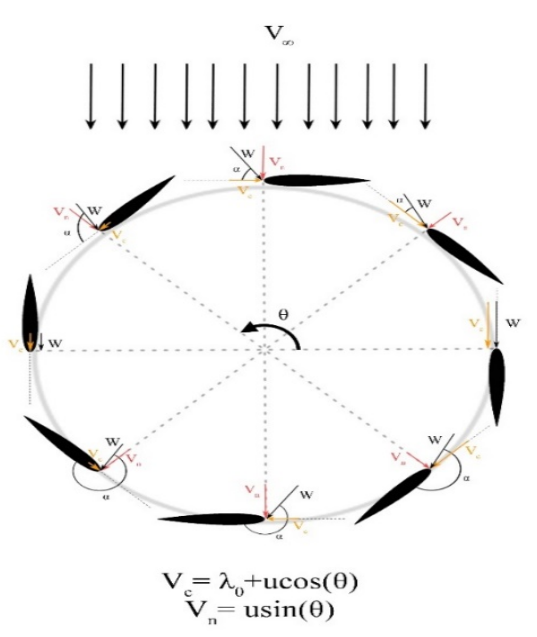

Fig.3 Relations between the azimuth angle and AOA at $\lambda<1$ 
The normal and tangential forces acting on blades can be determined by:

$$
\begin{aligned}
& F_{n}(\theta)=\frac{A_{p}}{A_{s}} C_{n}\left(\frac{W}{V_{\infty}}\right)^{2} \\
& F_{t}(\theta)=\frac{A_{p}}{A_{s}} C_{t}\left(\frac{W}{V_{\infty}}\right)^{2}
\end{aligned}
$$

The tangential force is used to calculate the torque near the centre of rotor, therefore:

$$
T_{u p}(\theta)=\frac{\rho c R H C_{t} W^{2}}{2}
$$

For the downstream of the rotor, all of the equations are repeated and the free wind velocity is substituted by equilibrium velocity which is determined from equation (5). The local relative wind speed, AOA and modified AOA equations are respectively defined as:

$$
\begin{aligned}
& W^{\prime}=(2-1) V_{\infty} \sqrt{\left(\frac{\lambda_{0}}{(2 u-1)}+u^{\prime} \sin (\theta)\right)^{2}+\left(u^{\prime} \cos (\theta)\right)^{2}} \\
& \alpha_{u}^{\prime}=\tan ^{-1}\left(\frac{u^{\prime} \cos (\theta)}{\frac{\lambda_{0}}{(2 u-1)}+u^{\prime} \sin (\theta)}\right) \\
& \alpha_{l}=\alpha_{u}^{\prime}+180\left(\left[\frac{\alpha_{u}^{\prime}}{\alpha_{u}^{\prime}+1}\right]-\left[\frac{\theta}{180}\right]\right)
\end{aligned}
$$

The induction factor in the downstream of rotor region is determined similar to that of the upstream region but the value of the induction factor in the downstream is less than upstream.

$$
\begin{aligned}
u^{\prime}= & \frac{\pi}{f_{d}+\pi} \\
f_{d}=\frac{\sigma}{2 \pi} \int_{\pi}^{2 \pi}\left(\frac{W}{V_{\infty}}\right)^{2} & |\sec (\theta)|\left(C_{n}^{\prime} \cos (\theta)\right. \\
& \left.-C_{t}^{\prime} \sin (\theta)\right) d \theta
\end{aligned}
$$

After calculating the induction factor for downstream region, the $\mathrm{C}_{n}{ }^{\prime}$ and $\mathrm{C}_{t}{ }^{\prime}$ which are the coefficients of normal and tangential components of the force, respectively, are obtained from equations (25) and (26), respectively.

$$
\begin{aligned}
& C_{n}{ }^{\prime}=C_{L} \cos \left(\alpha^{\prime}\right)+C_{D} \sin \left(\alpha^{\prime}\right) \\
& C_{t}^{\prime}=C_{L} \sin \left(\alpha^{\prime}\right)-C_{D} \cos \left(\alpha^{\prime}\right)
\end{aligned}
$$

The components of the force that acting on the blades in downstream is determined by equations (27) and (28).

$$
\begin{aligned}
& F_{n}(\theta)=\frac{A_{p}}{A_{s}} C_{n}{ }^{\prime}\left(\frac{W^{\prime}}{V_{\infty}}\right)^{2} \\
& F_{t}(\theta)=\frac{A_{p}}{A_{s}} C_{t}{ }^{\prime}\left(\frac{W^{\prime}}{V_{\infty}}\right)^{2}
\end{aligned}
$$

The generated torque and power coefficients from downstream region are expressed as follows:

$$
\begin{aligned}
& T_{\text {down }}(\theta)=\frac{\rho c R H C_{t}^{\prime} W^{\prime 2}}{2} \\
& \bar{C}_{P_{\text {down }}}=\frac{\sigma}{4 \pi} \int_{\pi}^{2 \pi} C_{t}\left(\frac{W^{\prime}}{V_{\infty}}\right)^{2} d \theta \\
& C_{P_{\text {down }}=\lambda_{0} \cdot \bar{C}_{P_{\text {down }}}}
\end{aligned}
$$

Finally, the total power coefficient of the rotor is obtained by adding the power coefficient of each region (Sumantraa et al., 2014), as:

$$
C_{p}=C_{P_{\text {up }}}+C_{P_{\text {down }}}
$$

\subsection{Numerical model \\ 2.3.1. Governing equations and solution methodology}

The flow was considered incompressible, because the flow velocities in the domain were much smaller than the speed of sound. The Unsteady Reynolds Averaged Navier Stokes (URANS) equations were used and the turbulence model was solved with SST k- $\omega$ model based on the previous studies (Chaiyanupong \& Chitsomboon, 2018). In this study, all of the simulations were performed with commercial CFD software Fluent from ANSYS 17.2. Sliding Mesh technique was used for rotatory domain. Intensity of inlet turbulence was under $5 \%$ and the SIMPLE algorithm with a second order implicit transient formulation was selected. All of the solution variables were calculated by second order upwind discretization scheme. For calculating the time steps, $1 \%$ of rotating domain was used for time steps. One cycle of rotor equal to $360^{\circ}$ was simulate for obtaining the results.

\subsubsection{Computational domain and mesh generating}

Two 2D domains, consisting of stationary and rotary domains, were created in CFD model. No-slip boundary was set to blade airfoils as a function of wall. Two edges of stationary domains were also defined as walls. A sliding interface boundary was defined for the separated domain region. The inlet and outlet sections were defined as different velocity inlet and pressure outlet, respectively. Figures (4), (5) and (6) show the CFD domain in ANSYS fluent software, mesh of all domains and the mesh around the airfoil, respectively.

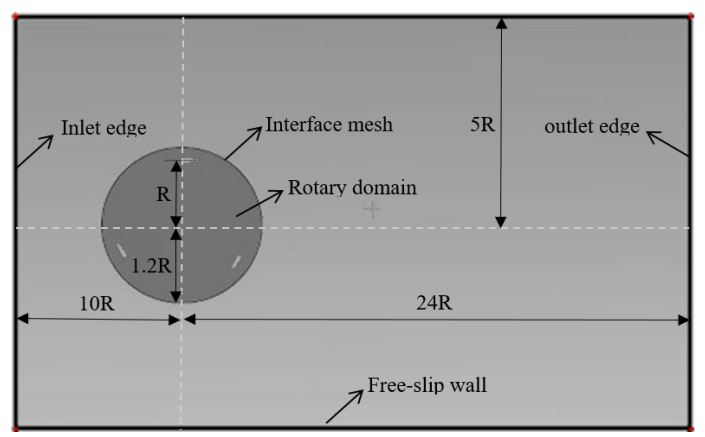

Fig. 4. Computational domains 


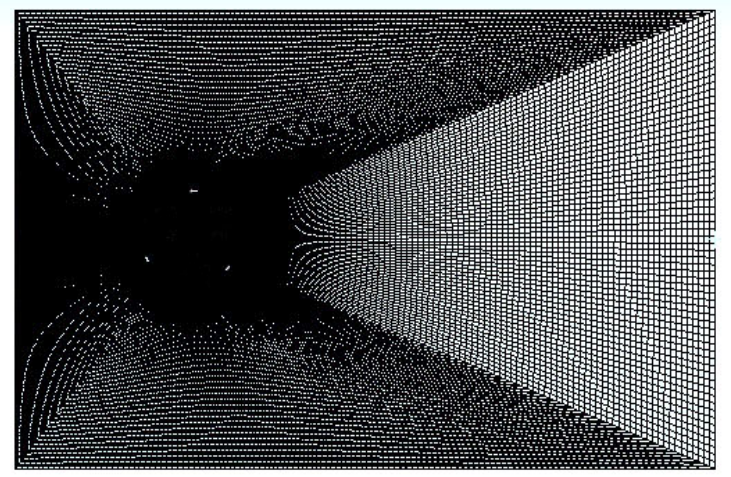

Fig. 5 The mesh generated for two rotary and stationary domains

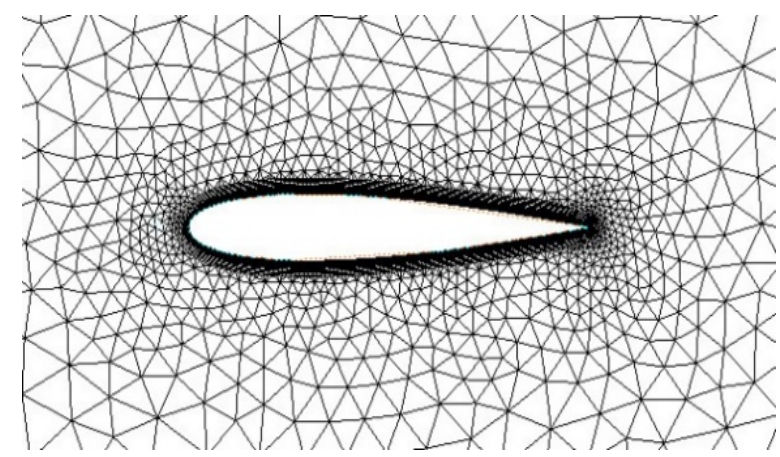

Fig.6 The mesh generated around airfoil

Soft meshes were employed for the rotary domain and to capture the boundary layer effect on the around the airfoils, inflation was set by 1.2 of growth rate and number of layers was 20. At first, the meshing process was applied by choosing fewer amount of elements and thus the average skewness index, orthogonal quality, aspect ratio and the number of elements and nods were studied. The parameters of 5 types of mesh with different division numbers for domains are shown in Fig. 7 and Fig. 8. The best mesh type that it was named (5) has better feature and more compatibility was selected and eventually applied. Total number of elements and nods in this mesh type was 98362 and 142305 in all domain structures, respectively also the $\mathrm{y}+$ value, skewness value and orthogonal quality is 1 and 0.623 and 0.789 , respectively.

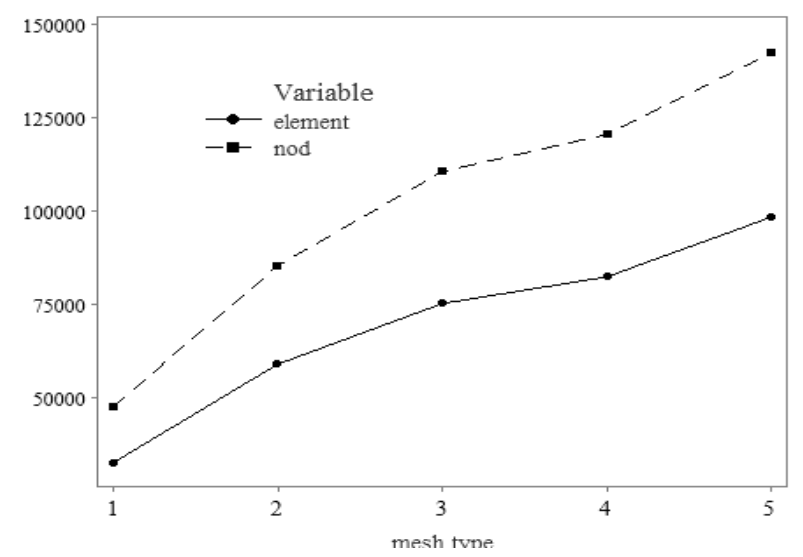

Fig. 7 Number of element and nods in the 5 different mesh types

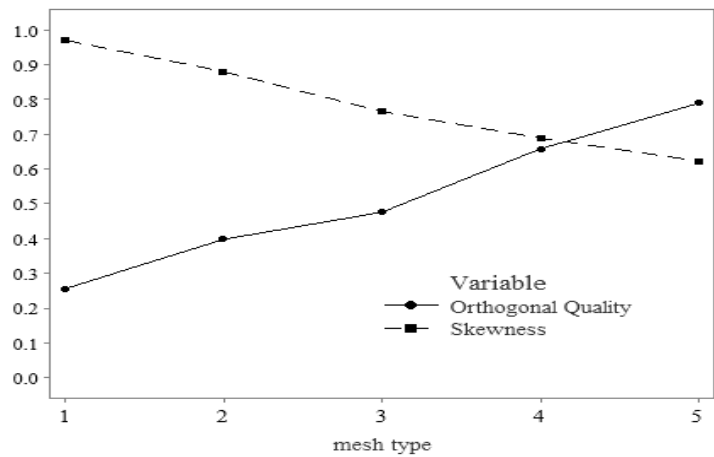

Fig. 8 Quality parameters of 5 different mesh types

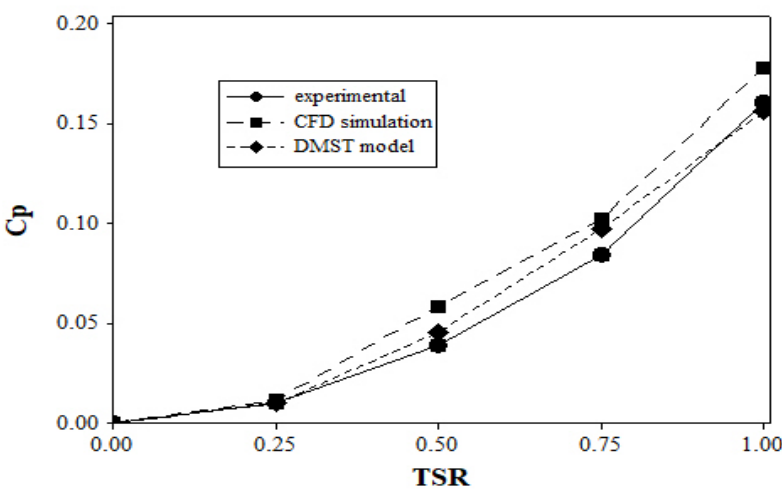

Fig. 9 Comparison of power coefficient in DMST model, CFD simulation and experimental results.

\subsubsection{Experimental Validation}

DMST model and numerical model solutions were verified by available validated data. Experimental results of the study of Darrieus wind turbine were reported by Elkhoury, Kiwata \& Aoun (2015). They numerically and experimentally investigated the performance of a micro scale $\mathrm{H}$ type three bladed Darrieus VAWT with high solidity $\sigma=0.75$, length of $0.8 \mathrm{~m}$ and diameters of $0.8 \mathrm{~m}$. It had a symmetrical blade profile (NACA 0018) with a chord length of $0.2 \mathrm{~m}$. Power coefficient at $\lambda<1$ with three wind velocities of 6,8 and $10 \mathrm{~m} . \mathrm{s}^{-1}$ was used for verifying the process. Figure 9 shows the comparison between experimental data, DMST model and numerical simulation. The results showed a relatively good match of estimated with experimental data. With assume the constant amount of velocity, frontal area and air density the relationship between power coefficient and power is the same.

\section{Result and Discussion}

Equation (9) was employed to calculate the AOA of inflow air on blades for DMST model. Figure (10) shows the three various $\lambda$ values $(<1)$ of the blades. From the figure it can be inferred that increasing $\lambda$ led to a decrease in the AOA. The lower value of AOA caused a higher lift force, however at $\lambda<1$ the AOA values is bigger than 90 degrees. Rotating at $\lambda<1$ is a result of the combination of lift and drag forces but at $\lambda \geq 1$, only the lift force causes the rotation. Hence, rotating at $\lambda<1$ is very important and can strongly affect the performance of the wind turbine. 


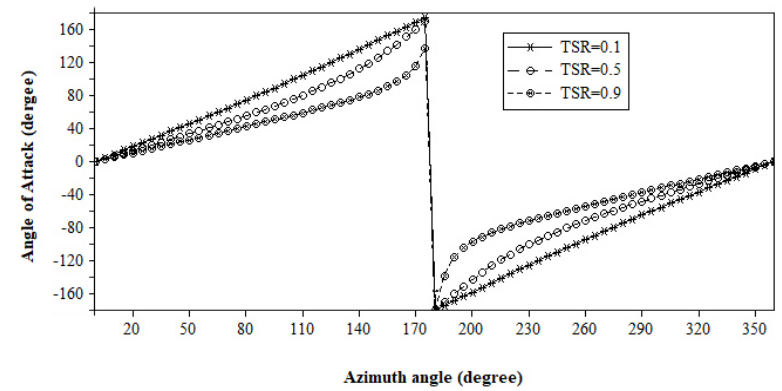

Fig. 10. AOA versus azimuth angle at different $\lambda$

The generated torque from DMST and CFD simulation at $\lambda=0.1$ (RT) for five wind turbines in various chord lengths are shown in Figure (11.A). Larger chord lengths of the blades cause larger drag and lift coefficients, and consequently larger generated torque compared to the blades with smaller chord lengths. According to the force equations, wind velocity is an important factor in the tangential force value. Accordingly, the torque increases at higher wind velocities. This trend can be found in many studies such as Dossena et al., (2015) and Dumitrescu et al., (2014). According to equation (2), rotating at higher wind velocity at $\lambda=0.1$ led to higher rotor angular velocity. Moreover, the generated torque increased at high wind velocity, so these two parameters led to the increment of generated power. A comparison between DMST model and CFD simulation result in the Figure (11.B) revealed a good relationship between them. Figure (11.C) shows the time turbines need to reach $\lambda=0.1$. The more time needed to reach $\lambda=0.1$, the harder the blades start rotation. The chord length directly affects the blade weight, so the moment of inertia of the rotor with larger chord length was higher. Increase in the moment of inertia at the low wind velocity resulted in difficult rotation of the rotor. Hara et al., (2012) found that increased moment of inertia decreased angular velocity at same wind velocity, so the results of this study was in agreement with their results. At $1 \mathrm{~m} / \mathrm{s}$ wind velocity, time to reach $\lambda=0.1$ for the $0.24 \mathrm{~m}$ chord length was 2.5 times more than $0.16 \mathrm{~m}$ chord length. Even though the high chord length wind turbines can generate higher torques, starting of these turbines is a big problem. Reduction of the chord length can solve the selfstarting problems; however, it may reduce the generated power. Therefore, the optimal value of the chord length and rotor solidity must be determined. Some aerodynamic effect cannot capture by mathematical model but CFD solution consider the aerodynamic effect like dynamic stall. This case led to see some differences between CFD and DMST results
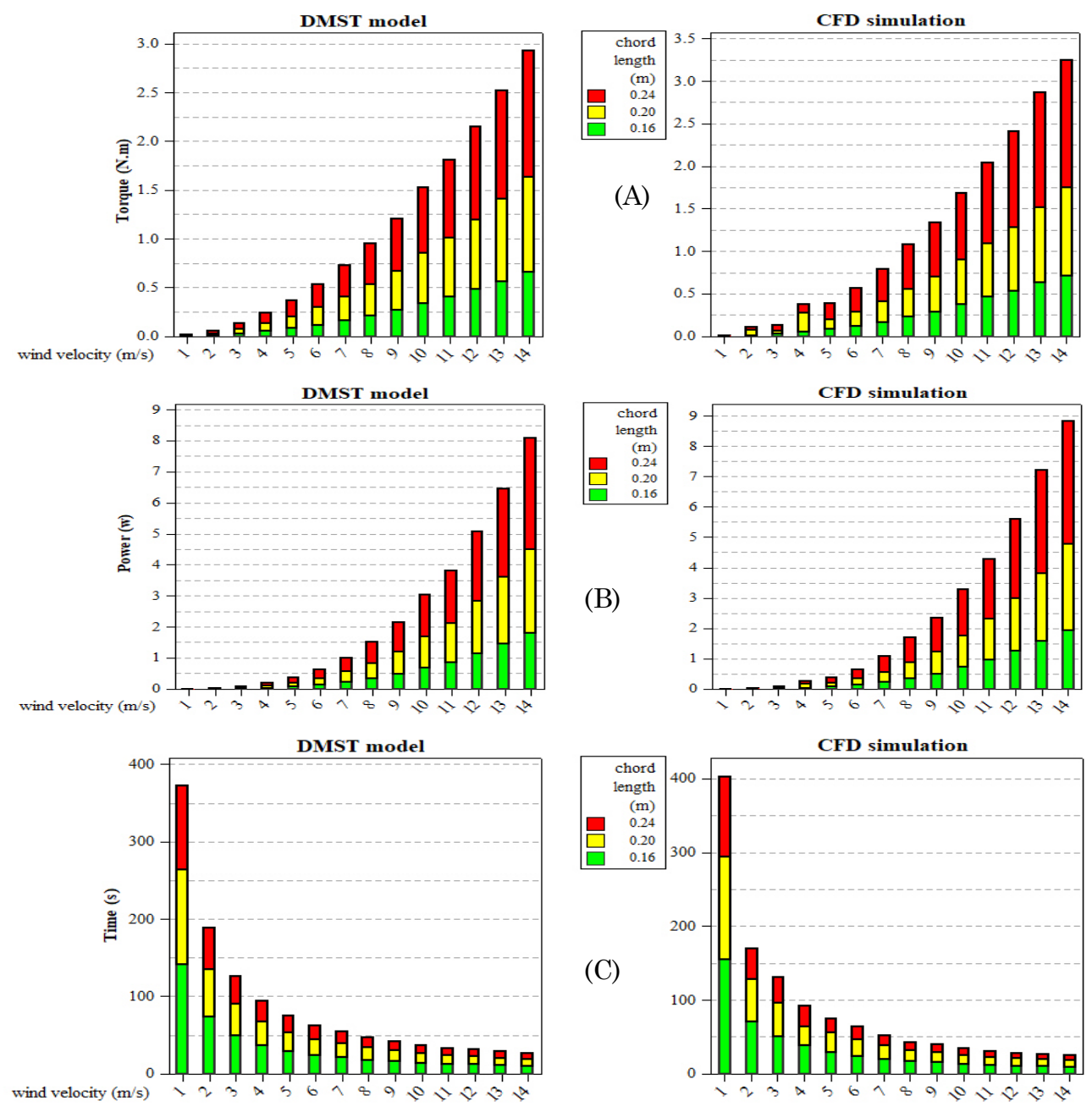

Fig. 11. Effect of chord length and wind velocity on (A) torque, (B) power generated and (C) time spend in DMST model (left) and CFD simulation (right) 


\subsection{Effect of blade solidity}

Results of the generated torque in various blade solidity of fifteen wind turbines from two analysis methods are shown in the Figure (12.A). The wind turbines with higher blade solidity generated higher torques. The generated torques and blade solidity did not follow a certain trend, but the fitted regression line for DMST model and CFD simulation result indicated a direct relationship between blade solidity and generated torque. Similar results were found in Singh, Biswas \& Misra (2015) research's The turbines with high blade solidity could generate higher power levels at $\lambda=0.1$. Figure (12.B) illustrates the relationship between power and blade solidity of H-rotor VAWTs. Some local data points did not follow the blade solidity trend, however, DMST model and CFD simulation presented an overall direct relation. The time to reach $\lambda=0.1$ for various wind turbines are shown in the Figure (12.C). Rotation of the wind turbine happens when the tangential force overcomes the rotation resistance. So, decreased the time to reach $\lambda=0.1$, implies that the rotation resistance of wind turbines is reduced. Furthermore, the increment of angular velocity slop for high solidity wind turbines is more than that for low solidity wind turbines. In the blade solidity of 0.6 , two different torques, powers and times were found, which revealed that some other design parameters, including $\mathrm{H} / \mathrm{D}$, could have influenced the H-rotor wind turbine performance.

\subsection{Effect of Reynolds number}

According to the Re number equation, the wind velocity and chord length are two effective parameters influencing Re number. Therefore, Re number can effectively change the wind turbine performance. Figure (13.A) shows the generated torque of the wind turbine in different $\mathrm{Re}$ numbers. Increase in generated torque occurred with increasing Re number.

Drag and lift coefficients at high wind velocity and high chord length increased, which led to the increment of generated torque and power. Figure (13.B) is the result of fifteen different generated powers at $\lambda=0.1$ of wind turbine at fourteen wind velocities from the two solution methods. Some variations observed in the generated power due to the differences of chord lengths and wind velocities. In the range of $1.5 \times 10^{5}$ to $1.7 \times 10^{5}$ of $\mathrm{Re}$ number, at first the generated power reduced from 1.46 and $1.6 \mathrm{~W}$ to 0.95 and $1.1 \mathrm{w}$ in DMST model and CFD simulation, respectively. Afterwards, it increased to 1.8 and $1.9 \mathrm{w}$ for DMST model and CFD simulation, respectively. The first point of this trend belonged to the chord length of $0.16 \mathrm{~m}$ and wind velocity of $13 \mathrm{~m} / \mathrm{s}$. The second point, which was minimum in this range, corresponded to the chord length of $0.24 \mathrm{~m}$ and wind velocity of $9 \mathrm{~m} / \mathrm{s}$. The maximum generated power in the above mentioned range was obtained for the chord length of $0.16 \mathrm{~m}$ and $14 \mathrm{~m} / \mathrm{s}$ wind velocity. According to Figure (13.C), which shows the time needed for the rotor to reach $\lambda=0.1$, increasing $\operatorname{Re}$ number led to shorter required time. The quantitative difference between the times required to reach $\lambda=0.1$ at high Re numbers was very low, however, the spent time strongly changed with the change in the Re number less than $0.7 \times 10^{5}$. In figure (13.C), an acceptable relationship between DMST model and CFD simulation results for calculating the time wind turbine needed to reach $\lambda=0.1$ was seen.
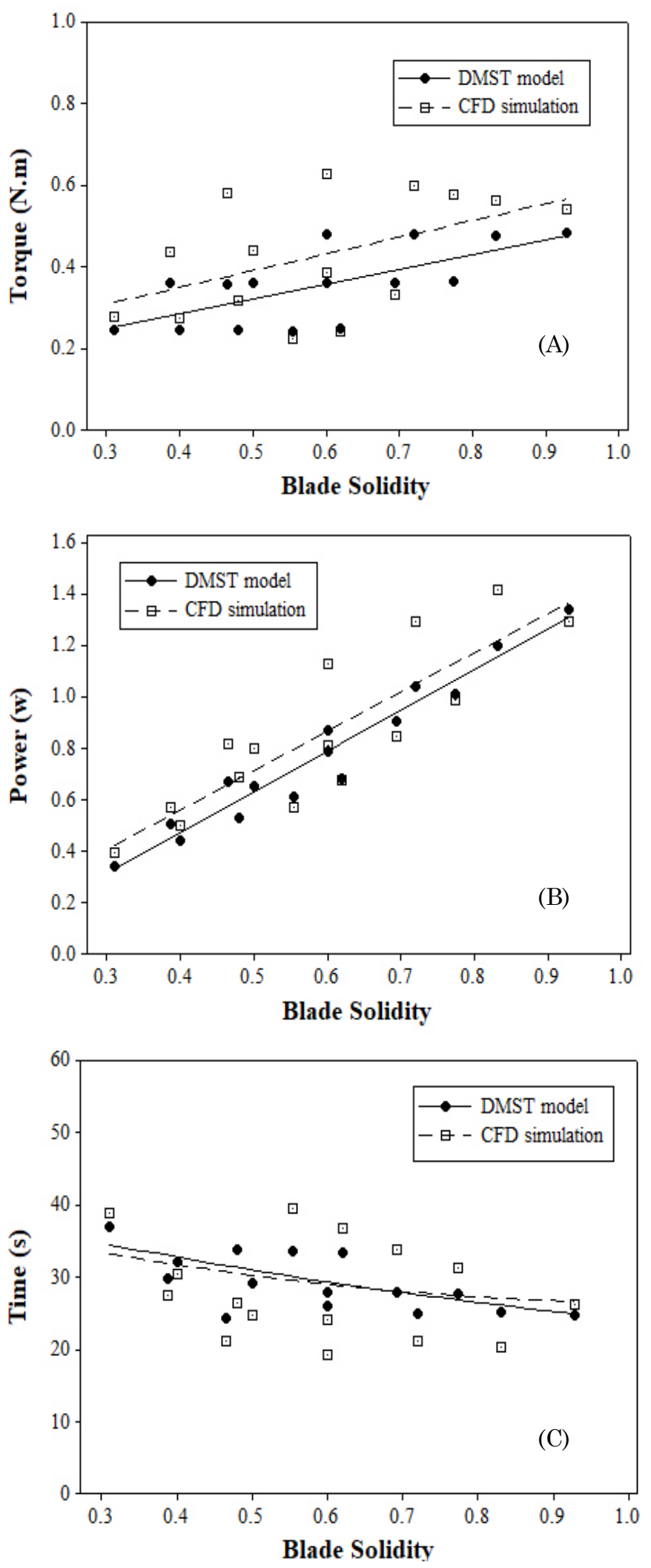

Fig. 12. Effect of blade solidity on (A) torque, (B) power generated and $(\mathrm{C})$ time spend in DMST model and CFD simulation. 

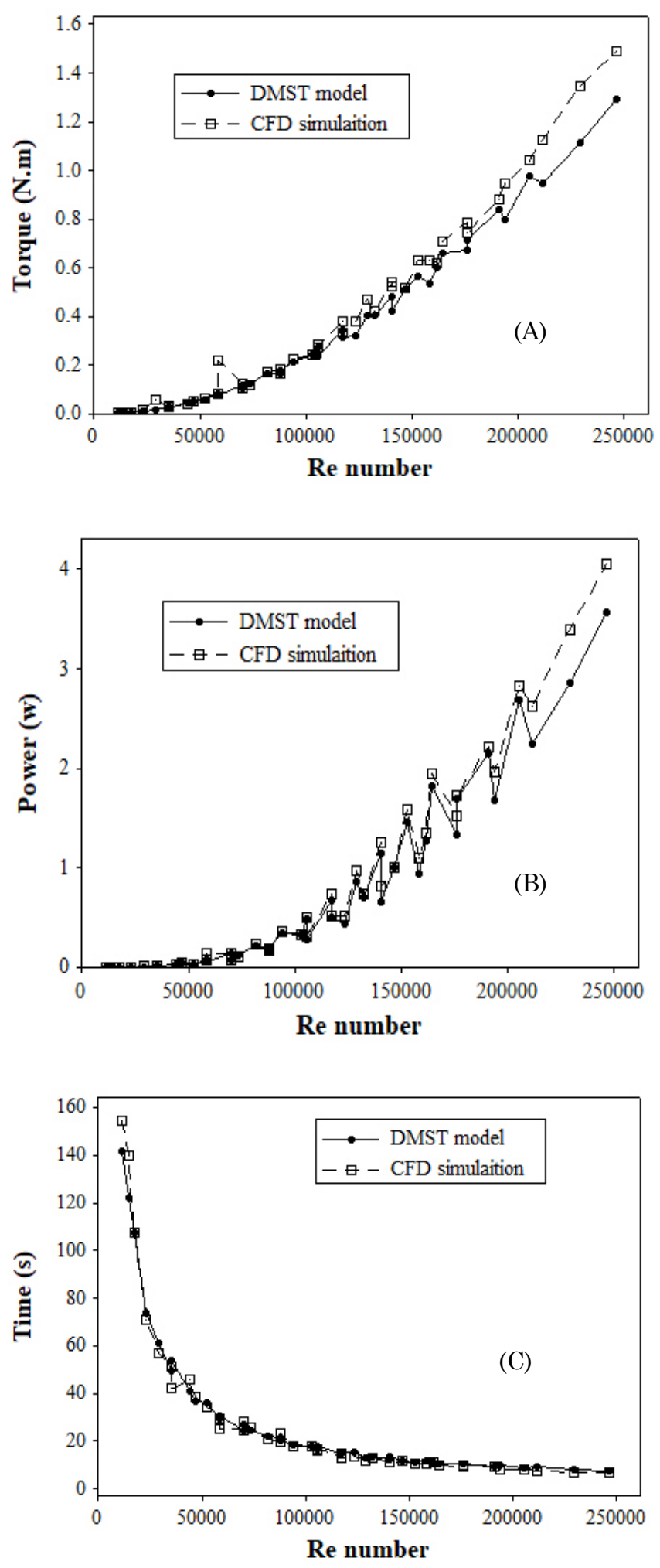

Fig. 13. Effect of Re number on (A) torque, (B) power generated and $(\mathrm{C})$ time spend in DMST model and CFD simulation.

\subsection{Effect of $H / D$ ratio}

The effect of H/D ratio on H-type Darrieus wind turbine performance at $\lambda=0.1$ was investigated. Figure (14) shows the result of determining the torque, power and the time needed to reach $\lambda=0.1$ for DMST model and CFD simulation of 210 situations of the wind turbines in different Re numbers. In the range of 0 to $0.9 \times 10^{5}$ of $R e$ number the differences among generated torque were not observable. The H/D ratio affects generated torque at high Re number $\left(2.5 \times 10^{5}\right)$, so the generated torque decreased as $\mathrm{H} / \mathrm{D}$ ratio increased but in the low Re number the H/D ratio has no direct relationship with torque generating. The maximum generated torque at high Re number was obtained from $0.83 \mathrm{H} / \mathrm{D}$ ratio. Furthermore, it was found that this trend was valid at $1 \times 10^{5}$ and $1.5 \times 10^{5}$ Re numbers. Similar results were observed in figure (14.A and 14.B). Generated power demonstrated different behavior compared to the torque. At high Re number, increment of $\mathrm{H} / \mathrm{D}$ ratio led to an increase in the power (figures 14. C and 14.D). The effect of H/D ratio was quite obvious, so that for the Re number of $2.4 \times 10^{5}$, the generated power increased by almost up to 2 times. At low Re numbers, this trend has not valid for power generating. The DMST model results showed different generated power values for various H/D ratio at $0.1 \times 10^{5}$ Re number. By fixing the frontal area $(\mathrm{H} \times \mathrm{D})$ of $\mathrm{H}$-type Darrieus wind turbines, the diameters of rotor increased in low H/D ratio, these turbines need a low angular velocity to reach $\lambda=0.1$. Angular velocity is an important parameter in power equation. Although the generated torque decreased by increasing H/D ratio, the generated power increased in high $\mathrm{H} / \mathrm{D}$ ratios due to the increment of angular velocity. At all $\lambda$ values of $H$-type Darrieus wind turbines, the rotor with high H/D ratio had a low torque generation capacity and a high angular velocity. The overall power generation was enhanced at high angular velocity. Figure (14.E and 14.F) shows the time needed for different wind turbines to reach $\lambda=0.1$ at various $R e$ numbers. The DMST model and CFD simulation results confirmed that the turbine with H/D ratio of around 1.2 could reach $\lambda=0.1$ more quickly than others. This case can observe in figure 14 .E at $0.1 \times 10^{5} \mathrm{Re}$ number and in the Figure $14 . \mathrm{F}$ at the Re number under $0.5 \times 10^{5}$.The maximum time needed to reach $\lambda=0.1$ at low Re number was obtained for H/D ratio of 2 .

Figure (15) illustrates the effect of H/D ratio of rotor on the torque, power and the time needed to reach $\lambda=0.1$ for DMST model and CFD simulation of 15 different types of wind turbines with various solidities. Figures (15.A) and (15.B) presents the results of determination of generated torque via two solution methods, respectively. The maximum torque generation was observed at low H/D ratio and low rotor solidity. However, in rotor solidity of 0.6 , the maximum torque generation region was at $\mathrm{H} / \mathrm{D}$ ratio of below 1 . For higher rotor solidities, the maximum torque generation corresponded to $\mathrm{H} / \mathrm{D}$ ratio of 1.6 . The best H/D ratio for generating the maximum torque of wind at different blade solidities is indicated in figures (15.A) and (15.B). Changes in turbine power generation at various blade solidity and H/D ratio from the two solution methods is shown in the Figure (15.C and 15.D).

At the low TSR (under 3), a direct relation between solidity and power generation has been reported in previous studies (Rezaeiha, Montazeri \& Blocken 2018; Eboibi, Danao \& Howell 2016). The best H/D ratio of rotor depends on solidity, so to generate more power in low solidity, it's better to select a high H/D ratio. Although, the acceptable H/D ratio for solidity of 0.6 is below 1 . 


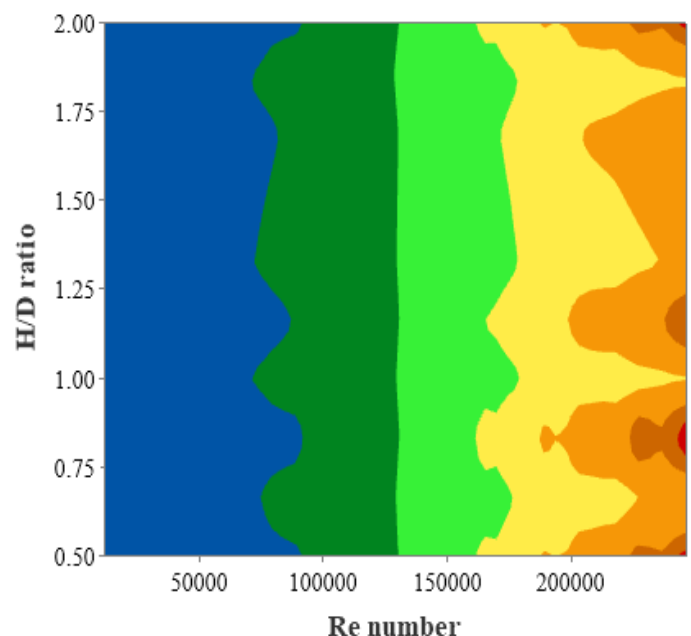

(A)

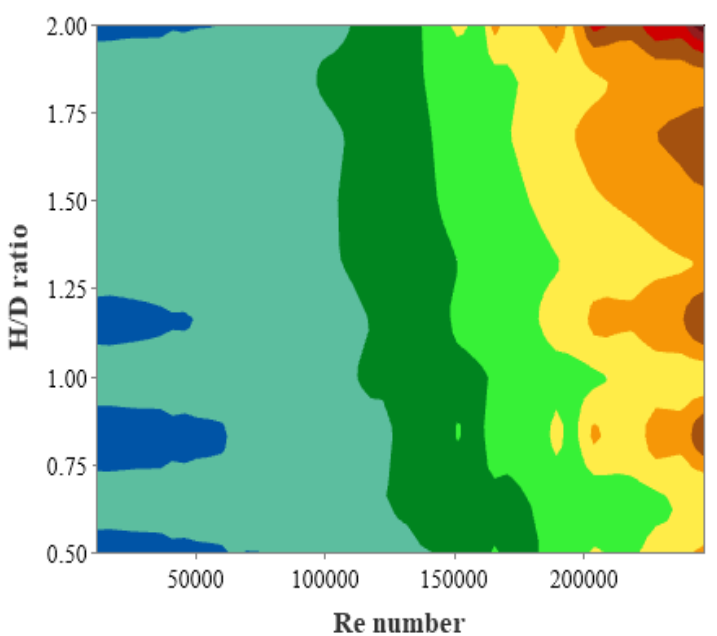

(C)

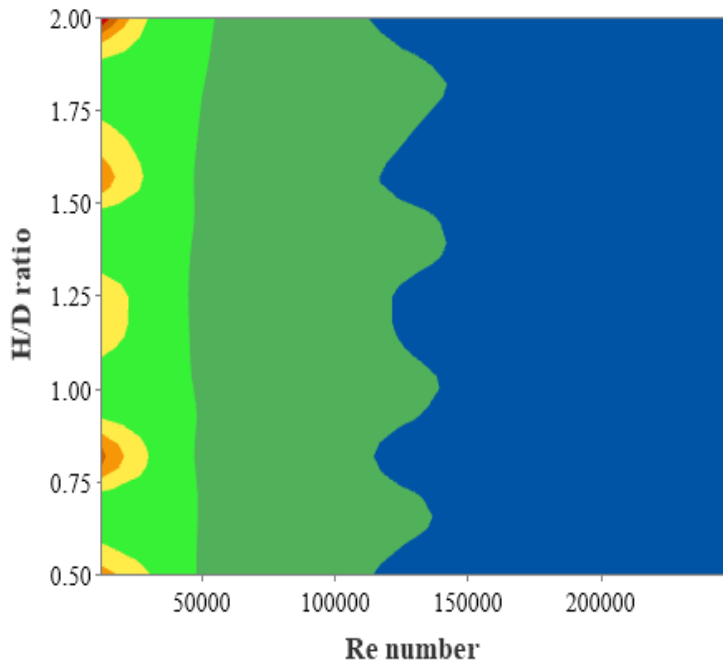

(E)
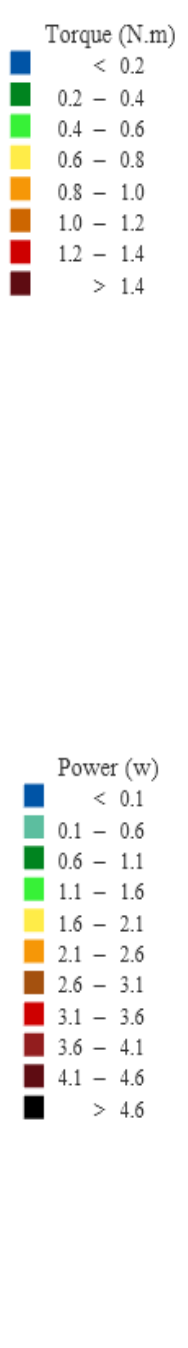

Time (s)
$<20$
$20-40$
$40-60$
$60-80$
$80-100$
$100-120$
$120-140$
$>140$

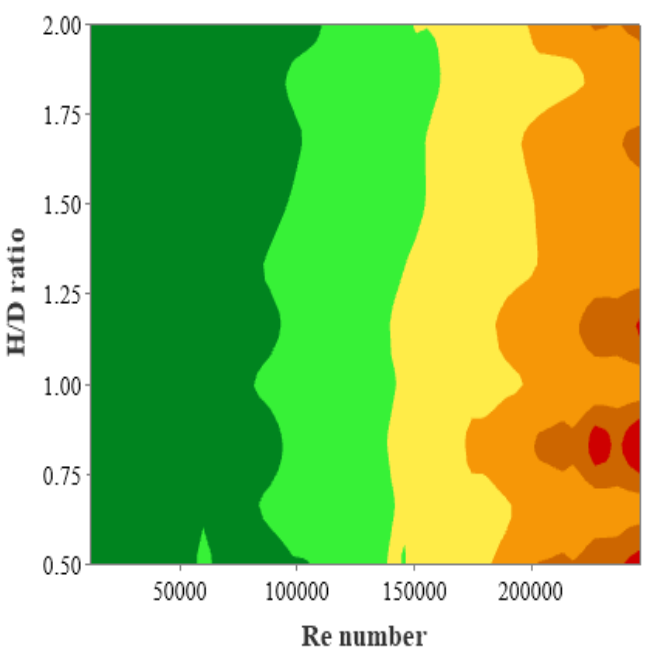

Torque (N.m)
$<0.003$
$0.003-0.269$
$0.269-0.535$
$0.535-0.801$
$0.801-1.067$
$1.067-1.333$
$1.333-1.599$
$>1.599$

(B)

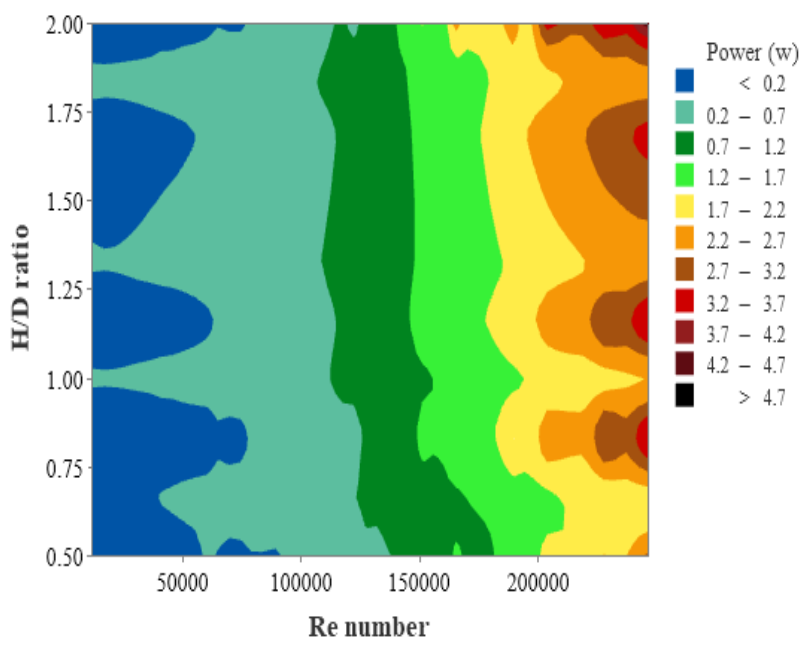

(D)

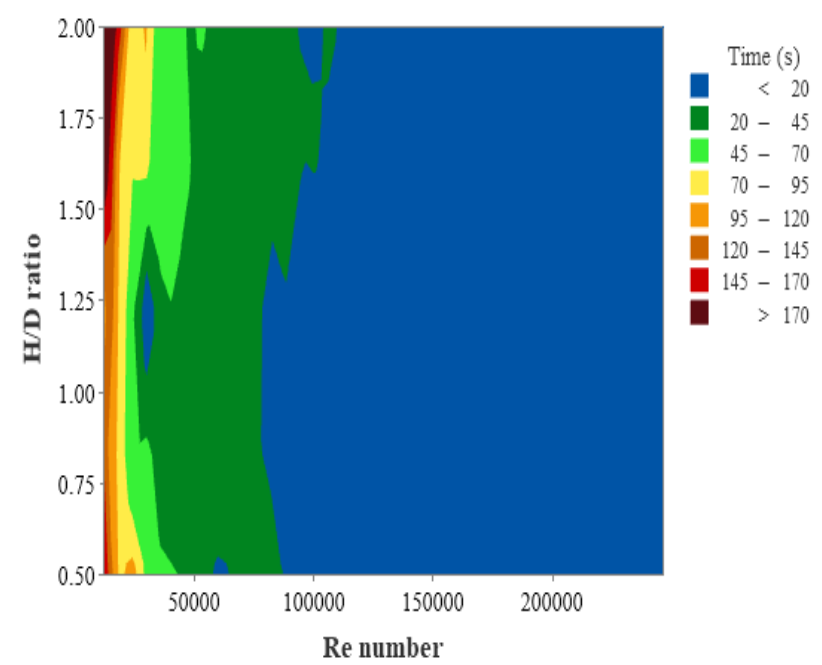

(F)

Fig. 14. Contour plot of H/D ratio in various Re number for (A, B) torque, (C, D) power generated and (E, F) time in (DMST model, CFD simulation) 


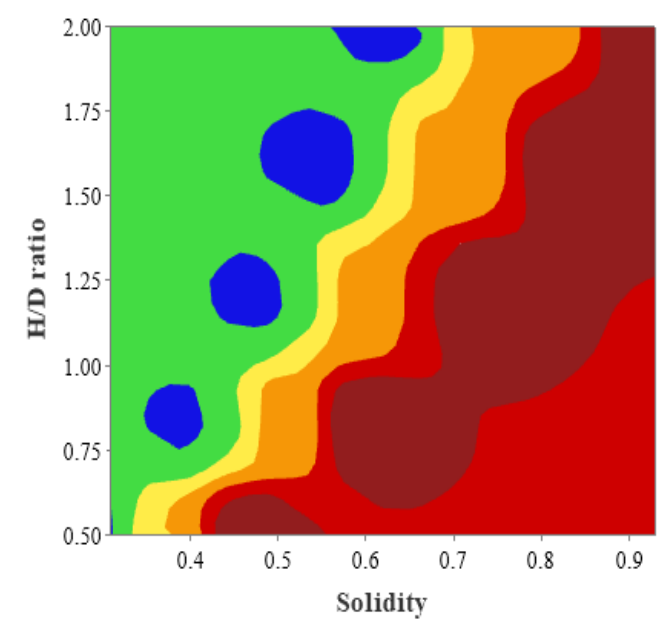

(A)

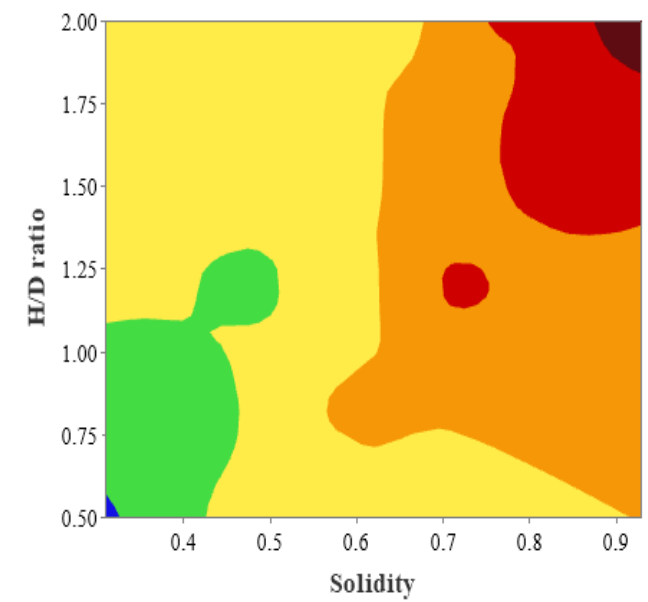

(C)

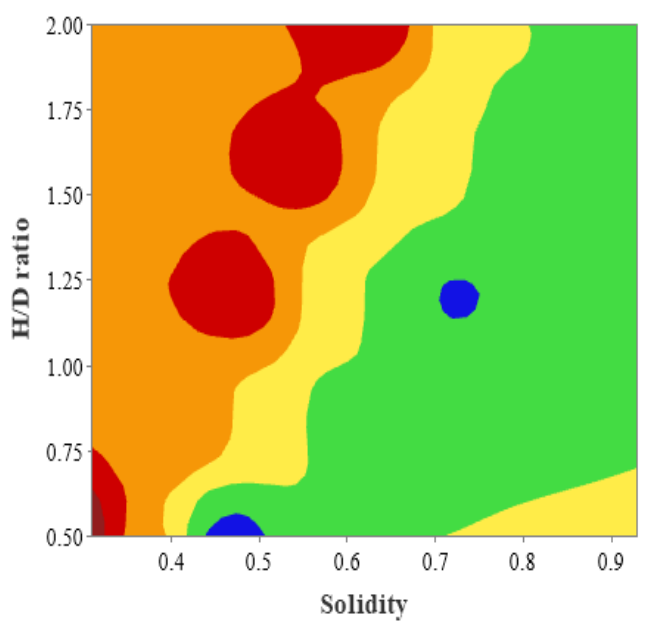

(E)

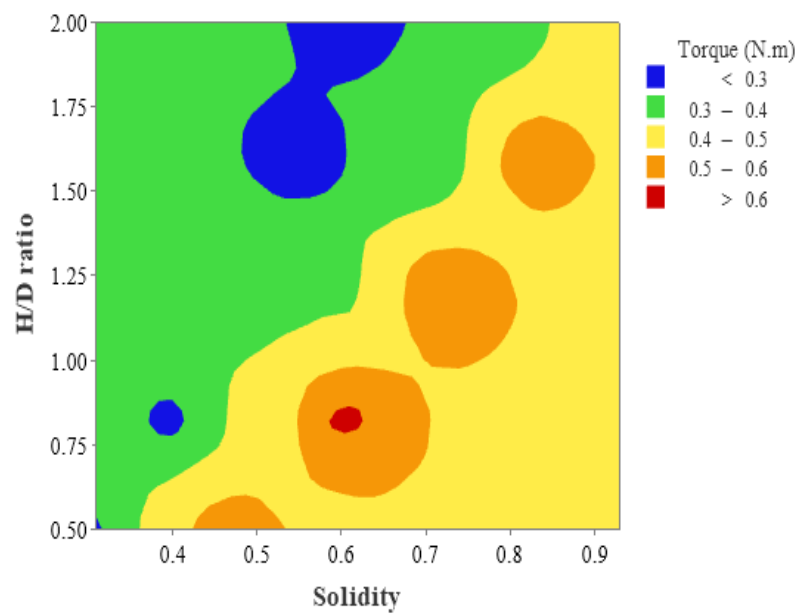

(B)

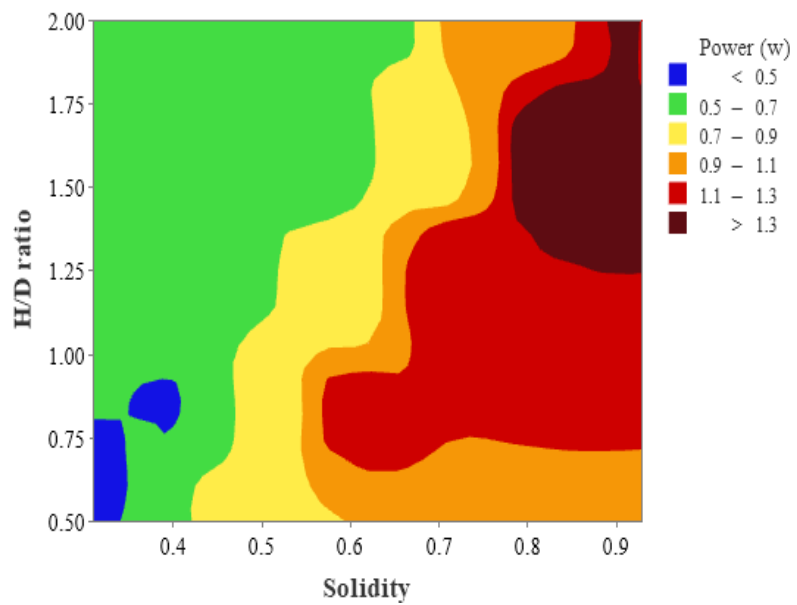

(D)

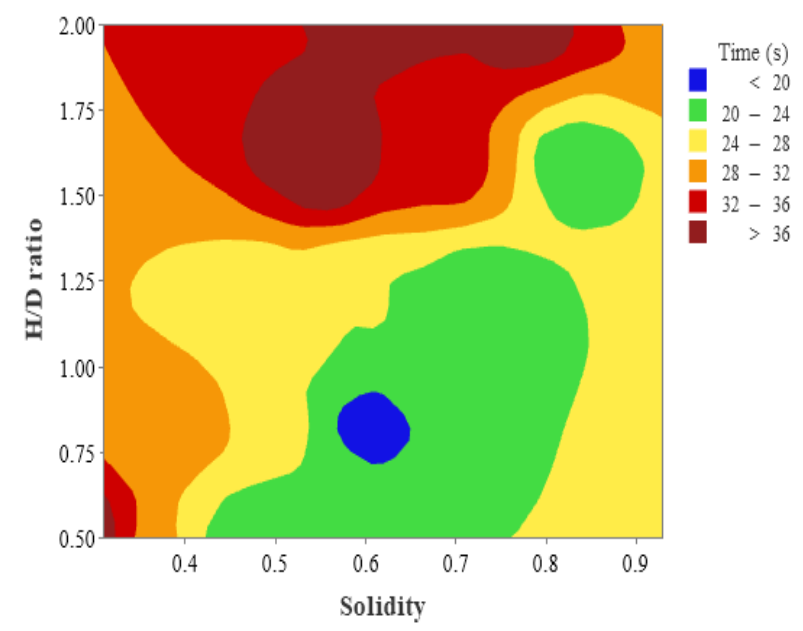

(F)

Fig. 15. Contour plot of H/D ratio in various solidity for (A, B) torque, $(C, D)$ power generated and (E, F) in (DMST model, CFD simulation) 


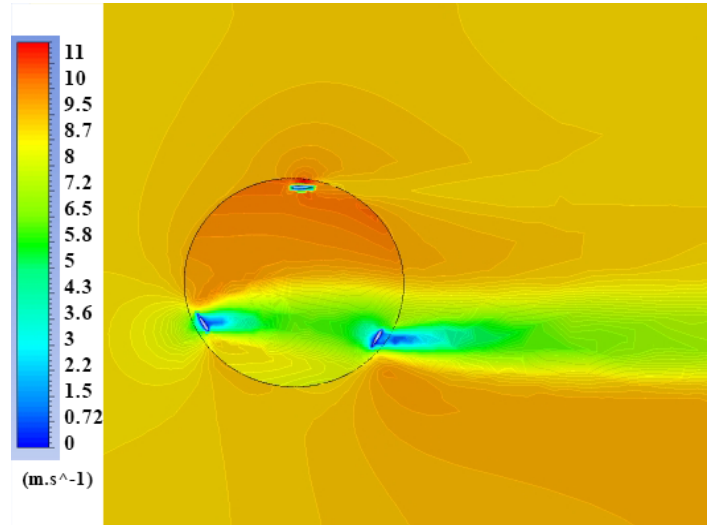

Fig. 16. Velocity contour of the wind turbine

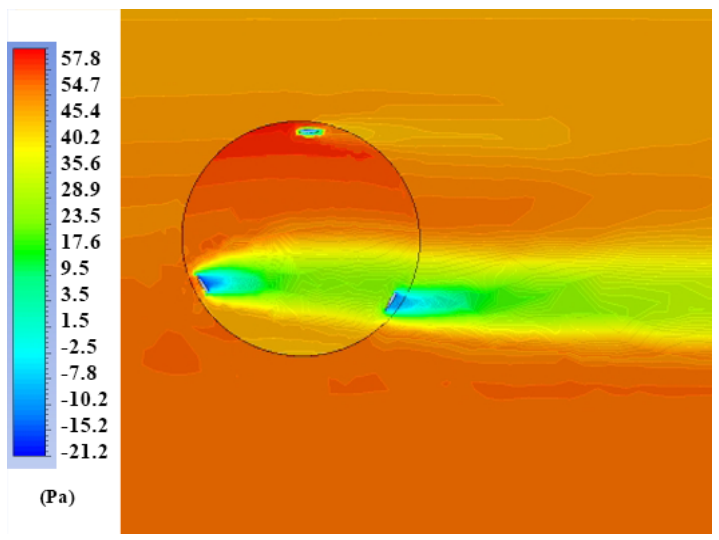

Fig. 17 Pressure contour of wind turbine

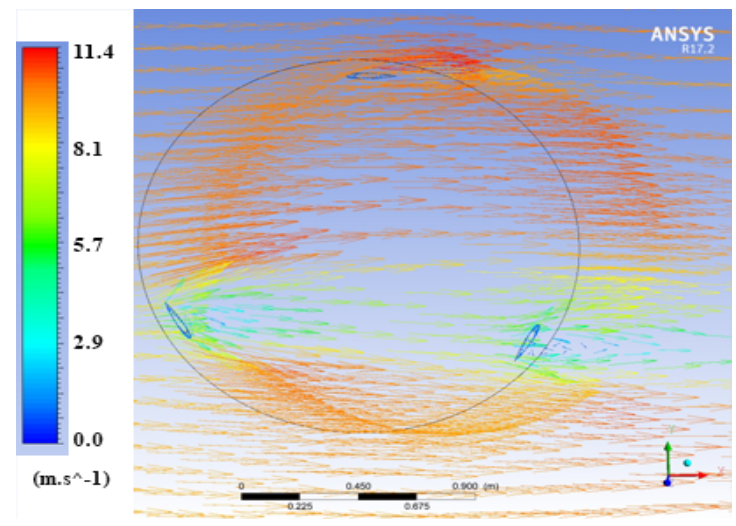

Fig. 18. Vectors around the blade of wind turbine

The maximum power obtained from the wind turbine with solidity of 0.9 and $\mathrm{H} / \mathrm{D}$ ratio of 2 . This result was also confirmed by DMST model and CFD simulation results. Figure (15.E and 15.F) shows the results of DMST model and CFD simulation for the time wind turbines needed to reach $\lambda=0.1$. As presented by the contour plot of generated torque, the maximum value regions had minimum spend time. Hence, for low solidities, increasing H/D ratio could reduce the time needed to reach $\lambda=0.1$. Similar to the generated torque contour plots, the H/D ratio below 1 at solidity of 0.6 needed minimum time. Although some differences were observed between DMST model and CFD simulation results at the high $\mathrm{H} / \mathrm{D}$ ratio, the overall spent time behaviour for the two solution methods was similar.

\subsection{Simulation results}

The results of the CFD simulation of H-type Darrieus wind turbine are shows in the figure $(16-18)$. The wind velocity is $8 \mathrm{~m} \cdot \mathrm{s}^{-1}$ and the rotor rotate in the 0.1 of $\lambda$. The blade solidity of this wind turbine is 0.6 and H/D ratio is 1.2. In the Table 1 number of this wind turbine is 8 . Figure 16 shows the velocity contour, the blades number 2 and 3 have +120 and -120 angle of attack respectively so the drag coefficient increased and led to decreasing in the air velocity after them. Each 3 blades experiences high and low AOA, which causes a complex air flow pattern. The existence of these complex vorticities, leads to a slower, or even no starting of the turbine, which may be mainly due to the lower lift force of the blade. That this event led to the starting problems of the H-type of Darrieus wind turbines. In the Figure 16, the boundary layer effect around the blade led to the wind velocity of this location be zero.

Pressure contour plotted in the Figure 17 and can be concluded that pressure dropped after blade 2 and 3 but the decreasing in the pressure in the blade number 1 is not significant led to its AOA. The velocity vectors also plotted in the Figure 18, it can be expressed that with increasing in density of the vectors, the pressure increased. Irregular directions of the vector show the turbulence of the wind flow. The size of the vortex that appeared after blades diminished by increasing of $\lambda$ due to decreasing in AOA (Cheng et al., 2017). In this simulation the $\lambda$ is 0.1 that as expected the size of vertex is big. In the upwind region in compared with downwind region, blades rotate among the intact and higher wind velocity of air flow. Blade 1 and 2 located in the upwind region and confront with $8 \mathrm{~m} \cdot \mathrm{s}^{-1}$ but the blade number 3 located in the downwind region and confront with the $5.5 \mathrm{~m} . \mathrm{s}^{-1}$ of wind flow. So the generated torque in the up wind region is higher than downwind region. This result also presented in the other researches (Sumantraa et al., 2014). A closer look will show that the pressure dropped when the air flow passed the blades number 2 and 3. But in the front of this blades pressure increased, although the velocity decreased in the front of blades. Stream lines of wind flow around blades showed in the Figure (19-21). The change in the direction of the stream lines is not noticeable in the around blade number one in the Figure 19. The unsteady flow after crossing the blades number 2 and 3 is showed in the Figure 20 and 21 that numerical solution can capture that.

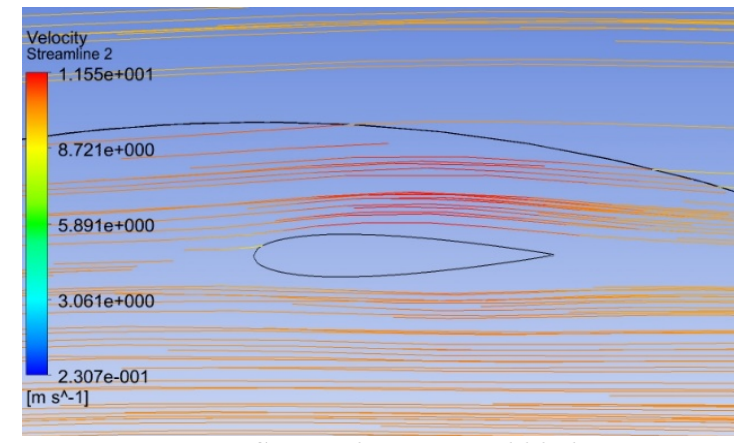

Fig. 19. Stream lines around blade 1 


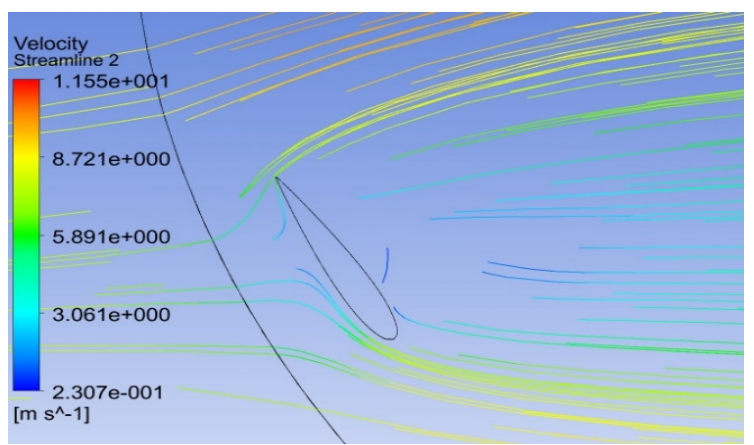

Fig. 20. Stream lines around blade 2

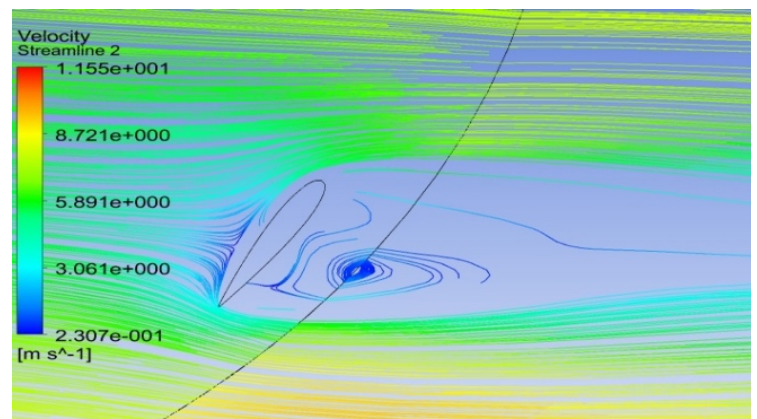

Fig. 21 Stream lines around blade 3

\section{Conclusion}

Using the new modified equations to determine the attack angle of Darrieus wind turbine at $\lambda$ below 1 is a new approach to characterize the wind turbine. DMST model and CFD solution with URANS equations and SST k- $\omega$ turbulence model presented an acceptable contribution to determination of the wind turbine performance in this study. Based on our results, it was found that the peak of generated power (in the range of design parameters) obtained at $2.5 \times 10^{5}$ Re number, 0.91 solidity and H/D ratio of 2 . However, design parameters must be redefined for other situations. The lowest time needed for turbine to reach $\lambda=0.1$ was in the range of 0.6 to 0.7 solidities and 0.8 to 1.2 of $\mathrm{H} / \mathrm{D}$ ratios, however, increasing Re number decreased the time.

\begin{tabular}{lll}
\multicolumn{2}{l}{ Nomenclature } & \\
$\mathrm{Ap}$ & $:$ & blade planform area \\
$\mathrm{As}$ & $:$ & rotor swept area \\
$\mathrm{C}$ & $:$ & friction number \\
$\mathrm{C}$ & $:$ & blade chord length \\
$\mathrm{Cd}$ & $:$ & drag coefficient \\
$\mathrm{Cl}$ & $:$ & lift coefficient \\
$\mathrm{Cn}$ & $:$ & normal aerodynamic force coefficient \\
$\mathrm{Cp}$ & $:$ & power coefficient of the wind turbine \\
$\mathrm{Ct}$ & $:$ & tangential aerodynamic force coefficient \\
$\mathrm{D}$ & $:$ & diameter of the rotor \\
$\mathrm{Fn}$ & $:$ & aerodynamic tangential force \\
$\mathrm{H}$ & $:$ & blade length \\
$\mathrm{I}$ & $:$ & moment of inertia \\
$\mathrm{N}$ & $:$ & $N$ number of the blades \\
$\mathrm{R}$ & $:$ & rotor radius \\
$\mathrm{Re}$ & $:$ & Reynolds number \\
$\mathrm{t}$ & $:$ & time \\
$\mathrm{T}$ & $:$ & torque \\
$\mathrm{W}$ & $:$ & wake velocity
\end{tabular}

$\mathrm{V} \infty$

$\mathrm{Ve}$

$\mathrm{V}^{\prime}$

$\mathrm{Vc}$

$\mathrm{Vn}$ axial induction factor

free wind velocity

equilibrium wind velocity in upstream

downstream velocity

chordal velocity component

normal velocity component

$\begin{array}{ll}\text { Greek letters } \\ \alpha_{1} & : \text { angle of attack for } \lambda<1 \\ \alpha \mathrm{u} & : \text { angle of attack for } \lambda \geq 1 \\ \theta & : \text { azimuthal angle } \\ \ddot{\Theta} & : \text { rotational acceleration of rotor } \\ \lambda & : \text { blade tip speed ratio } \\ \rho & : \text { density of air } \\ \sigma & : \text { rotor solidity } \\ \omega & : \text { rotational speed of rotor }\end{array}$

\section{Acknowledgment}

This research was supported by Iran National Science Foundation (INSF) with 98020209 number. We thank our colleagues from INSF who provided insight and expertise that greatly assisted the research.

\section{Reference}

Abdalrahman, G., Melek, W., \& Lien, F. S. (2017). Pitch angle control for a small-scale Darrieus vertical axis wind turbine with straight blades (H-Type VAWT). Renewable Energy, 114, 1353-1362. https://doi.org/10.1016/j.renene.2017.07.068

Abraham, J. P., Plourde, B. D., Mowry, G. S., Minkowycz, W. J., \& Sparrow, E. M. (2012). Summary of Savonius wind turbine development and future applications for smallscale power generation. Journal of Renewable and Sustainable Energy, 4(4). https://doi.org/10.1063/1.4747822

Ahmadi-Baloutaki, M. (2016). Analysis and Improvement of Aerodynamic Performance of Straight Bladed Vertical Axis Wind Turbines. ProQuest Dissertations and Theses, 196. Retrieved from https://search.proquest.com/docview/1767790874?accounti $\mathrm{d}=15300 \% 0 \mathrm{Ahttp}: / /$ resolver.ebscohost.com/openurl?ctx_ve $\mathrm{r}=$ Z39.88-2004\&ctx_enc=info:ofi/enc:UTF-

$8 \& r f r$ id=info:sid/Matericals+Science+\%26+Engineering+ Dissertations\&rft_val_fmt=info:ofi/fmt:kev:mtx:dissert

Alam, F., \& Golde, S. (2013). An Aerodynamic Study of a Micro Scale Vertical Axis Wind Turbine. Procedia Engineering, 56, 568-572. https://doi.org/10.1016/j.proeng.2013.03.161

Aslam Bhutta, M. M., Hayat, N., Bashir, M. H., Khan, A. R., Ahmad, K. N., \& Khan, S. (2012). CFD applications in various heat exchangers design: A review. Applied Thermal Engineering, 32, 1-12. https://doi.org/10.1016/j.applthermaleng.2011.09.001

Beri, H., \& Yao, Y. (2011). Effect of Camber Airfoil on SelfStarting of VAWT. Journal of Environmental Science and Technology, 302-312.

Chaiyanupong, J., \& Chitsomboon, T. (2018). Effects of turbulence models and grid densities on computational accuracy of flows over a vertical axis wind turbine. International Journal of Renewable Energy Development, 7(3), 213-222. https://doi.org/10.14710/ijred.7.3.213-222

Cheng, Q., Liu, X., Ji, H. S., Kim, K. C., \& Yang, B. (2017). Aerodynamic Analysis of a Helical Vertical Axis Wind Turbine. Energies, 10(575), 1-16.

Darrieus GJM. (1931). Turbine Having its rotating shaft 
transverse to the flow of the current.

Delafin, P. L., Nishino, T., Wang, L., \& Kolios, A. (2016). Effect of the number of blades and solidity on the performance of a vertical axis wind turbine. Journal of Physics: Conference Series, $\quad 753(2)$. https://doi.org/10.1088/17426596/753/2/022033

Dossena, V., Persico, G., Paradiso, B., Battisti, L., Dell'Anna, S., Brighenti, A., \& Benini, E. (2015). An experimental study of the aerodynamics and performance of a vertical axis wind turbine in a confined and unconfined environment. Journal of Energy Resources Technology, Transactions of the ASME, 137(5). https://doi.org/10.1115/1.4030448

Dumitrescu, H., Dumitrache, A., Popescu, C. L., Popescu, M. O., Frunzulică, F., \& Crăciunescu, A. (2014). Wind tunnel experiments on vertical-axis wind turbines with straight blades. Renewable Energy and Power Quality Journal, 1(12), 1001-1004. https://doi.org/10.24084/repqj12.562

Eboibi, O., Danao, L. A. M., \& Howell, R. J. (2016). Experimental investigation of the influence of solidity on the performance and flow field aerodynamics of vertical axis wind turbines at low Reynolds numbers. Renewable Energy, 92, 474-483. https://doi.org/10.1016/j.renene.2016.02.028

Elkhoury, M., Kiwata, T., \& Aoun, E. (2015). Experimental and numerical investigation of a three-dimensional verticalaxis wind turbine with variable-pitch. Journal of Wind Engineering and Industrial Aerodynamics, 139, 111-123. https://doi.org/10.1016/j.jweia.2015.01.004

Hara, Y., Hara, K., \& Hayashi, T. (2012). Moment of Inertia Dependence of Vertical Axis Wind Turbines in Pulsating Winds. International Journal of Rotating Machinery, 2012, 1-12. https://doi.org/10.1155/2012/910940

Islam, M., Fartaj, A., \& Carriveau, R. (2011). Design analysis of a smaller-capacity straight-bladed VAWT with an asymmetric airfoil. International Journal of Sustainable Energy, 30(3), 179-192. https://doi.org/10.1080/1478646X.2010.509496

Kirke, B. K., \& Paillard, B. (2017). Predicted and measured performance of a vertical axis wind turbine with passive variable pitch compared to fixed pitch. Wind Engineering, 41(1), 74-90. https://doi.org/10.1177/0309524X16677884

Letcher, T. M. (Trevor M. . (2017). Wind energy engineering : a handbook for onshore and offshore wind turbines. Retrieved from https://books.google.com/books/about/Wind_Energy_Engin eering.html?id=hRZ2DQAAQBAJ\&source=kp_cover

Liu, Q., Miao, W., Li, C., Hao, W., Zhu, H., \& Deng, Y. (2019). Effects of trailing-edge movable flap on aerodynamic performance and noise characteristics of VAWT. Energy, $189(\mathrm{xxxx})$ 116271. https://doi.org/10.1016/j.energy.2019.116271

Oliveira, A. T. De, Carolina, A., \& Maia, R. (2017). Analysis of a vertical axis wind turbine with blade pitch control analysis of a vertical-axis wind turbine with blade pitch control mechanism by Kimberlly Costa Carvalho, Rafael Alves da Silva Oriented by: Dietmar Rempfer Final Report for Summer Researc. (July 2016).

Paraschivoiu, I. (1988). Double-multiple streamtube model for studying vertical-axis wind turbines. Journal of Propulsion and Power, 4(4), 370-377. https://doi.org/10.2514/3.23076

Rezaeiha, A., Kalkman, I., \& Blocken, B. (2017). Effect of pitch angle on power performance and aerodynamics of a vertical axis wind turbine. Applied Energy, 197, 132-150. https://doi.org/10.1016/j.apenergy.2017.03.128

Rezaeiha, A., Montazeri, H., \& Blocken, B. (2018). Towards optimal aerodynamic design of vertical axis wind turbines: Impact of solidity and number of blades. Energy, 165, 1129-1148. https://doi.org/10.1016/j.energy.2018.09.192

Roy, S., Branger, H., Luneau, C., Bourras, D., \& Paillard, B. (2017). Design of an offshore three-bladed vertical axis wind turbine for wind tunnel experiments. Proceedings of the International Conference on Offshore Mechanics and Arctic Engineering - OMAE, 10(June). https://doi.org/10.1115/OMAE2017-61512

Saber, H. E., Attia, E. M., \& El Gamal, H. A. (2015). Analysis of Straight Bladed Vertical Axis Wind Turbine. International Journal of Engineering Research and Technology, 4(07), $714-723$.

Saeidi, D., Sedaghat, A., Alamdari, P., \& Alemrajabi, A. A. (2013). Aerodynamic design and economical evaluation of site specific small vertical axis wind turbines. Applied Energy, 101 , $765-775$. https://doi.org/10.1016/j.apenergy.2012.07.047

Sagharichi, A., Maghrebi, M. J., \& Arabgolarcheh, A. (2016). Variable pitch blades: An approach for improving performance of Darrieus wind turbine. Journal of Renewable and Sustainable Energy, 8(5). https://doi.org/10.1063/1.4964310

Singh, M. A., Biswas, A., \& Misra, R. D. (2015). Investigation of self-starting and high rotor solidity on the performance of a three $\mathrm{S} 1210$ blade H-type Darrieus rotor. Renewable Energy, 76, 381-387. https://doi.org/10.1016/j.renene.2014.11.027

Staelens, Y., Saeed, F., \& Paraschivoiu, I. (2003). A straightbladed variable-pitch VAWT concept for improved power generation. ASME 2003 Wind Energy Symposium, WIND2003, 146-154. https://doi.org/10.1115/wind2003524

Sumantraa, R. B., Chandramouli, S., Premsai, T. P., Prithviraj, P., Vivek, M., \& Kishore, V. R. (2014). Numerical analysis of effect of pitch angle on a small scale vertical axis wind turbine. International Journal of Renewable Energy Research, $4(4)$ https://doi.org/10.20508/ijrer.50726

Sun, X., Zhu, J., Hanif, A., Li, Z., \& Sun, G. (2020). Effects of blade shape and its corresponding moment of inertia on selfstarting and power extraction performance of the novel bowl-shaped floating straight-bladed vertical axis wind turbine. Sustainable Energy Technologies and Assessments, $\quad 38$ (January), 100648. https://doi.org/10.1016/j.seta.2020.100648

Wu, Z., Bangga, G., \& Cao, Y. (2019). Effects of lateral wind gusts on vertical axis wind turbines. Energy, 167, 1212-1223. https://doi.org/10.1016/j.energy.2018.11.074 